\title{
A recurrent question from a primary care physician: How should I treat my COVID-19 patients at home? An update
}

\author{
Fredy Suter $^{1 \#}$, Norberto Perico ${ }^{2 \#}$, Monica Cortinovis ${ }^{2}$ and Giuseppe Remuzzi ${ }^{1,2 *}$ \\ ${ }^{1}$ Azienda Sociosanitaria Territoriale - Ospedale Papa Giovanni XXIII, Bergamo, Italy \\ ${ }^{2}$ Istituto di Ricerche Farmacologiche Mario Negri, IRCCS, Bergamo, Italy

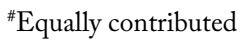

\section{Introduction}

How can I take care of my patients with initial symptoms of COVID-19 at home?

This is a recurrent question from primary care physicians, particularly in less fortunate parts of the world. We have received several questions about this from Latin America, for instance, and just yesterday from Bolivia. Our first answer is always, do not expect to rely on results from controlled trials. If you are fortunate, it will take you 3 years to find an answer, which will then be contradicted by the next trial. By then, either the virus will have disappeared or a vaccine will have become available. So, what to do? You can only rely on the very scarce evidence you may find in the literature and your own knowledge to manage your patients' symptoms, and take advantage of the experience gained by one of us (F.S.), who is a long-term scholar of infectious diseases and who used his experience and common sense to treat over 50 COVID-19 patients at home, some of them needed oxygen for transient respiratory distress, and only 3 of whom needed to be admitted to hospital.

To guarantee the minimum protection and safety of patients, healthcare workers, and visitors to hospitals, the World Health Organization (WHO) has provided a set of standard minimum requirements that must be put in place both at the national level and in all health facilities to prevent and control infections [1]. This approach could also be useful for managing COVID-19 in low- and middleincome countries, where it should be ensured as soon as possible that these minimum prerequisites are in place [2]

The newly recognised disease COVID-19 is caused by the severe acute respiratory syndrome coronavirus 2 (SARS-CoV-2), which by early December 2019 had spread from China to the rest of the world, especially Europe and the United States [3], with over 50 million confirmed cases and over 1.200 .000 deaths in 190 countries $\left(9^{\text {th }}\right.$ November, 2020) [3]. The clinical spectrum of SARS-CoV-2 infection is wide, encompassing asymptomatic infection, mild upper respiratory tract illness, and severe viral pneumonia with respiratory failure and even death [4]. According to retrospective data from China regarding 1099 patients with laboratory-confirmed COVID-19 [5], at the time of admission to hospital, the most common symptoms were cough (67.8\%), fever (43\%), and fatigue (38.1\%), and less frequently myalgia/ arthralgia (14.9\%), a sore throat (13.9\%) and headache (13.6), while nausea or vomiting $(5.0 \%)$ and diarrhoea $(3.8 \%)$ were uncommon. Similar clinical characteristics are also encountered in European and US COVID-19 patients in the early phase of the infection.
Given the rising global death toll associated with the pandemic, in the past few months we have witnessed a race to find drugs/biologic treatments to save the lives of hospitalised, severely ill patients, as well as to develop vaccines [6,7]. To this end, randomised clinical trials are underway, including the SOLIDARITY trial launched on $20^{\text {th }}$ March by WHO which is characterised by its simplicity, to test experimental drug candidates or repurposed medicines. Therapeutic approaches to the early, mild phase of COVID-19 are also being debated, and here, too, there is an emphasis on the need for randomised clinical trials. However, there are times, like the present, when the focus is mainly on containing the epidemic and providing relief to hospitals dealing with unprecedented demands being made on their workforce in caring for COVID-19 patients. At this time, it is crucial to provide recommendations to primary care physicians, especially those practicing in resource-poor settings, on treating patients in the early phase of COVID-19 with initial mild symptoms at home. These measures may apply to conditions beyond the in-depth pathophysiology of the illness.

This is an update of our recommendations that focuses on a combination of two drug classes that target the most common symptoms and prophylactic therapy and oxygen therapy, when needed [8]. These are based on the pharmacological rationale and the available clinical evidence of efficacy in COVID-19 patients, including results of published randomized clinical trials, for each of our recommended class of drugs.

Recommended treatments should start immediately when COVID-19 early symptoms appear without waiting results of a nasopharyngeal swab, if any.

\section{Anti-inflammatory drugs}

Myalgias, arthralgias and fever are common symptoms of a mild COVID-19 infection that highlight an inflammatory process. Thus, the rationale for the use of anti-inflammatory agents is to limit host inflammatory responses to the viral infection.

${ }^{\star}$ Correspondence to: Giuseppe Remuzzi, Istituto di Ricerche Farmacologiche Mario Negri IRCCS, Centro Anna Maria Astori, Parco Scientifico Tecnologico Kilometro Rosso, Via Stezzano 87, 24126 Bergamo, Italy, Tel: +39.035.42131; E-mail: giuseppe.remuzzi@marionegri.it

Received: November 14, 2020; Accepted: November 23, 2020; Published: November 30, 2020 


\section{Non-steroidal anti-inflammatory drugs (NSAIDs):}

Should the patient have myalgias/arthralgias or other painful symptoms, our advice is to administer a cyclooxygenase-2 (COX-2) inhibitor, including nimesulide and celecoxib. Nimesulide is readily available, and at a high dose maximally inhibits the COX-2 enzyme [9]. Therefore, we recommend this drug at the oral dose of $100 \mathrm{mg} /$ twice a day (after a meal) for a maximum of 12 days. Alternatively, celecoxib (if not contraindicated) is recommended at an initial oral dose of $400 \mathrm{mg}$, followed by a second dose of $200 \mathrm{mg}$ on the first day of therapy. In the following days up to a maximum of $400 \mathrm{mg} /$ day (200 $\mathrm{mg}$ twice a day) should be given as needed.

Should the patient have fever $\left(\geq 37.3^{\circ} \mathrm{C}\right)$ or develop laboratory signs of hepatotoxicity associated with nimesulide or there are contraindications to celecoxib, these drugs should be substituted with aspirin (a COX-1 and COX-2 inhibitor) (500 mg twice a day p.o. - after a meal). Indeed, nimesulide can associate with a small risk of acute liver injury [10-12], very low when the drug is administered at recommended time of exposure and daily dosages [13]. Notably, nimesulide has also a good antipyretic effect.

These treatments should be associated with a proton pump inhibitor (e.g. lansoprazole - $30 \mathrm{mg} /$ day; or omeprazole - $20 \mathrm{mg}$ /day; or pantoprazole - $20 \mathrm{mg} /$ day). Paracetamol (acetaminophen) should not be used since it has very mild, if any, anti-inflammatory activity.

After approximately 3 days from the onset of symptoms (or more days have elapsed and the physician sees the patient for the first time), a series of hematochemical tests should be performed (blood cell count, D-dimer, CRP, creatinine, fasting blood glucose, ALT). Should inflammatory indexes (CRP, neutrophil count), ALT, and D-dimer be in the normal range, treatment with nimesulide/celecoxib (or aspirin) alone will continue.

NSAIDs are a class of medicines that act by inhibiting two enzymes, prostaglandin synthase 1 and 2 (also known as cyclooxygenase-1, COX-1, and cyclooxygenase-2, COX-2) [14]. Upon their activation, COX-1 and COX-2 produce, from the cell membrane lipid arachidonic acid, a series of prostaglandins that, in addition to having vasoactive effects, also participate in the process that eventually triggers fever and pain [15]. Concerns regarding the use of NSAIDs in respiratory tract infections were raised by a recent review of case-controlled studies in community-acquired pneumonia in adult and paediatric patients [16]. The results show higher rates of complications after respiratory tract infections in patients given NSAIDs than in those not treated with these medicines, including pleural effusion, prolonged illness, peritonsillar abscess, and the spread of infection to more than one site. Evidence from case-controlled studies, however, cannot clearly highlight a causality between NSAID prescription and complications [17]. There is also trial evidence from primary care settings that suggests that NSAIDs may prolong illness or cause complications when taken during respiratory tract infections [18]. Nonetheless, there is no scientific evidence to indicate that NSAID consumption puts patients who might otherwise have mild or asymptomatic SARS-CoV-2 infections at risk of developing a more severe form of the disease [19,20]. Moreover, in patients with mild respiratory tract illness, anti-inflammatory therapies may prevent fatal cytokine storms induced by SARS-CoV-2 in the lungs. This can at least be hypothesised for the NSAID aspirin, which has been shown to reduce plasma levels of interleukin 6 (IL-6), C-reactive protein (CRP), and macrophage colony stimulating factor in patients with chronic stable angina [21], and also for the COX-2 inhibitor celecoxib. Intriguingly, recent evidence supports a role for aspirin as a potential adjunctive therapy in COVID-19. A retrospective, multicentre cohort study on 412 adult patients hospitalised with COVID-19, 98 of whom received low-dose aspirin within 24 hours of admission or 7 days prior to admission, showed that aspirin use was independently associated with reduced risk of mechanical ventilation, intensive care unit admission, and in-hospital mortality [22]

Acetaminophen (paracetamol), a NSAID that inhibits both COX1 and COX-2 enzymes [20], has very mild anti-inflammatory activity $[23,24]$, and is therefore less preferable for non-hospitalised patients with COVID-19. Nevertheless, it should be considered that COX2 produces most of the prostaglandins relevant to inflammation and pain [16]. NSAIDs that inhibit COX-2 (nimesulide or celecoxib) are of value in treating myalgias and/or arthralgias or other painful symptoms in patients with COVID-19. Moreover, the use of NSAIDs could help these patients to sleep by relieving musculoskeletal symptoms and fever at night. Notably, recent evidence has highlighted crosstalk between sleep and immune system function that is relevant to sustaining immune defenses [25].

Although selective inhibition of COX-2 is desirable to limit the gastrointestinal toxicity seen with nonselective COX inhibitors $[9,26,27]$, physicians may be aware of the finding that long-term use of NSAIDs has been associated with higher rates of myocardial infarction and heart failure [28], but in real-world population-based observational studies these findings are debated [29]. What has been established is that long-term NSAID treatment may cause nephrotoxicity, which is exacerbated by fever and dehydration [30,31]. This is particularly true for elderly people, who may already have reduced kidney function related to ageing or concomitant chronic kidney disease, and the maintenance of renal blood flow is critically dependent on vasodilator prostaglandins. In Europe, COVID-19 largely - though not exclusively - affects elderly individuals, so family physicians should counsel elderly patients to hydrate adequately while taking NSAIDs, and use these drugs for the shorter possible period of time.

\section{Corticosteroids}

Few days later, especially if even mild symptoms (fever, myalgias/ arthralgias, or pain) persist, the hematochemical tests (without fasting blood glucose) should be repeated. When these tests indicate even mild increase of inflammatory indexes (CRP, neutrophil count) or fever, myalgias, arthralgias persist or cough and oxygen saturation $\left(\mathrm{SpO}_{2}\right)<94-92 \%$ occur, a thorax X-ray at bed should be performed, and corticosteroids could be considered as add-on treatment at home to further decrease the underlying inflammatory processes in COVID-19 patients.

We recommend corticosteroids not only as add-on treatment to manage musculoskeletal symptoms and fever, but also for their antiinflammatory properties in the presence of inflammatory markers, such as higher than normal CRP. Thus, our advice is that physicians prescribe oral dexamethasone ( $8 \mathrm{mg}$ for 3 days, then tapered to $4 \mathrm{mg}$ for another 3 days, and then to $2 \mathrm{mg}$ for 3 days. This makes $42 \mathrm{mg}$ dexamethasone total over 9 days). Nonetheless, the duration of corticosteroid treatment depends also on the clinical evolution of the disease.

Corticosteroids exert their anti-inflammatory effects mainly by inhibiting many pro-inflammatory genes that encode cytokines, chemokines, cell adhesion molecules, inflammatory enzymes and receptors to control the inflammatory process and restore homeostasis [32]. In viral pneumonia, corticosteroids are often also used as an auxiliary treatment to decrease the host inflammatory response in the 
lung, which may lead to acute lung injury and acute respiratory distress syndrome (ARDS). However, delays in viral clearance, and the increased risk of secondary infections and other complications, could outweigh the benefits of steroid treatment. This concern has been anticipated in earlier observational studies in patients with other severe communityacquired coronavirus pneumonias, such as those induced by SARS and MERS, which showed improved survival with corticosteroids, but also prolonged presence of viruses in the respiratory tract and blood and a high incidence of complications, including hyperglycemia, psychosis, and avascular necrosis [33-35]. At variance, a meta-analysis of over 6500 patients with influenza pneumonia documented that there was a higher risk of mortality and secondary infections in those given corticosteroids [36]. This is confirmed by results from a very recent meta-analysis of 15 studies (5270 patients) on the effects of corticosteroid treatment on critical and non-critical patients with coronavirus pneumonia (mainly SARS and MERS infections), including a small subgroup with SARS$\mathrm{CoV}-2$ infection [37]. The results, which are limited by the heterogeneity of these studies, showed that patients with severe conditions were more likely to require corticosteroid therapy, which, however, was associated with a higher rate of mortality and bacterial infection. This conclusion is at variance with a retrospective study in a cohort of 201 Chinese patients that reported that, in those who developed ARDS, methyprednisolone administration was linked to a lower risk of death than for patients who did not receive corticosteroid treatment [38]. Consistent with these findings were the results of the RECOVERY trial, a large open-label randomized controlled study enrolling 6425 patients hospitalized with COVID-19 (2104 randomized to receive dexamethasone and 4321 randomised to receive usual care). Treatment with dexamethasone (6 $\mathrm{mg} /$ day for up to 10 days) reduced mortality by one-third in patients receiving mechanical ventilation, and by one-fifth in those receiving supplemental oxygen compared to usual care alone. Nevertheless, there was no benefit among patients not receiving respiratory support [39]. The usefulness of corticosteroids has been confirmed by a living systematic review and network meta-analysis, supported by a prospective meta-analysis, with data from eight randomised trials (7184 participants), showing that systemic corticosteroids probably reduce 28-day mortality in patients with severe and critical COVID-19 [40]. Based upon these data, on $2^{\text {nd }}$ September 2020 a living WHO guidance strongly recommended for systemic corticosteroids in patients with severe and critical COVID-19. Along this line, a consensus statement from the Chinese Thoracic Society recommended a short course of corticosteroids at a low-to-moderate dose for critically ill patients with COVID-19 pneumonia [41,42]. Other investigators have also reported that low-dose corticosteroid treatment that is of brief duration can be beneficial in the clinical management of hospitalised critical patients with severe SARS-CoV-2 pneumonia [43]. Moreover, the Italian Lazzaro Spallanzani National Institute for Infectious Diseases has released updated recommendations for the clinical management of COVID-19 that include the administration of methyprednisolone or dexamethasone in patients with ARDS or severe respiratory failure [44]. All these observations, however, relate to hospitalised patients with severe pneumonia and respiratory failure. In contrast, during the early phase or in mild forms of COVID-19, when patients were not hospitalised, there appeared to be some evidence that corticosteroids may have been beneficial [45]. Indeed, the initial lesions in the lungs of most of these patients may be minimal at chest radiography, but the lesions can spread to the entire lung fields within a day. Prompt intervention with corticosteroids can reverse or at least attenuate these initial events [46]. Because the pathogenesis of pneumonia may be the same in all infected patients regardless of age, early control of immune/ inflammatory-mediated lung injury can also be helpful in reducing morbidity and possibly mortality for these patients $[47,48]$.

\section{Anticoagulant/anti-platelet agents}

\section{Low-molecular weight heparin}

When the hematochemical tests (the first or the second set) show even a mild increase of $\mathrm{D}$-dimer, our recommendation is to start treatment with low-molecular weight (LMW) heparin. Moreover, COVID-19 is a particularly debilitating illness, even for patients with mild symptoms, so patients are often bedridden for several weeks. They are therefore exposed to the risk of thromboembolic events, independently of age, and anticoagulant prophylaxis with heparin may be recommended. Our suggestion is to administer low-molecular weight (LMW) heparin, enoxaparin, at the prophylactic dose (daily dose of 4000 U.I subcutaneously - i.e. $40 \mathrm{mg}$ enoxaparin. Treatment is recommended for at least 7-14 days, independently of the patient recovering mobility).

Heparin activates anti-thrombin III, which in turn inhibits thrombin, Factor $\mathrm{X}$ and other proteases involved in the blood coagulation cascade [49]. Thus, LMW heparin, a glycosaminoglycan with anticoagulant activity, is commonly used prophylactically to prevent post-surgical venous thromboembolism, as well as in nonsurgical patients with acute heart failure or acute respiratory failure, conditions characterised by hypo-mobility. In addition, LMW heparin is the pharmacological treatment for deep vein thrombosis, pulmonary embolism and acute coronary syndrome.

Apart from causing patients to be bedridden, there is evidence that in coronavirus infections, including SARS-CoV-2, dysregulation of the coagulation cascade and fibrinolytic systems occur [50], creating a high risk of death for patients. Indeed, in a recent Dutch report on severely ill patients hospitalised in ICUs, $31 \%$ experienced thrombotic complications [51]. This is in line with a study showing that, in Irish patients admitted to hospital with severe COVID-19 infection, abnormal blood clotting occurred, causing micro-clots within the lung [52]. These patients had a significantly worse prognosis and were more likely to require ICU admission [52]. Similarly, a large retrospective study of adult COVID-19 patients in Wuhan, China, that reported that blood levels of $\mathrm{D}$-dimer - a marker of coagulation activation - that were higher than $1 \mu \mathrm{g} / \mathrm{ml}$ at hospital admission were associated with an 18 fold increase in mortality risk [4]. Others have reported that, compared to surviving COVID-19 patients, those who died had higher blood levels of D-dimer and prolonged prothrombin time at hospitalisation, and lower fibrinogen blood concentration at 10 to 14 days after hospital admission, indicating a state of hyper-coagulability [53]. Moreover, a pooled analysis of six original studies encompassing 1355 hospitalised patients with moderate to critical COVID-19, confirmed that D-dimer levels were significantly associated with the risk of mortality [54]. Furthermore, in the autopsies of the first patients who died of COVID-19 performed in Chinese hospitals as well as in our hospital in Bergamo, Italy, microthrombi were found not only in the lungs, but also in other organs, including the liver, kidneys and heart [55-57]. In addition, fibrin deposits are found in the lung parenchyma of patients with SARS-CoV-2 and ARDS [58]. These thrombotic/thromboembolic events are promoted by the inflammatory process underlying viral infections like SARS-CoV-2. In these patients, inflammation induces excessive production of thrombin and a reduction in fibrinolysis caused by endothelial dysfunction due to the ongoing viral infection [59]. Moreover, the hypoxia that characterises SARS-CoV-2 infection also contributes to thrombosis by enhancing blood viscosity [59].

Together, these observations led us to consider using prophylactic doses of heparin in hospitalised COVID-19 patients. A retrospective 
study in Wuhan on 449 hospitalised COVID-19 patients with severe pneumonia, 99 of whom received LMW heparin for 7 days or longer, showed that among patients with markedly elevated D-dimer ( $>6$-fold of the upper limit of normal) or sepsis-induced coagulopathy (SIC) criteria $>4$, the 28 -day mortality was significantly lower in heparin users than in non-users [60]. The study provides evidence that anticoagulant therapy with LMW heparin is associated with a better prognosis in severe COVID-19 patients with markedly elevated D-dimer or those who met the SIC criteria [60]. Similarly, a retrospective analysis of 2,733 COVID-19 patients hospitalised within the Mount Sinai Health System in New York showed that $29 \%$ among those on mechanical ventilation who received systemic anticoagulation died as compared to $63 \%$ of those who did not receive the treatment [61]. Moreover, evidence indicates that LMW heparin therapy in COVID-19 patients improved coagulation dysfunction [62]. Based on available information, the International Society on Thrombosis and Haemostasis (ISTH) suggested monitoring $\mathrm{D}$-dimer, prothrombin time and platelet count in all patients who present with COVID-19 infection [63]. ISHT has also recommended that all COVID-19 patients admitted to hospital be treated with prophylactic doses of LMW heparin, unless contraindicated (e.g., ongoing bleeding or platelet count $<25 \times 10^{9} / \mathrm{L}$ ) [63]. ISTH has recently updated its recommendations for using LMW heparin or unfractionated heparin in special COVID-19 patient populations, such as those with renal impairment or with obesity. In particular, obese individuals should be given a weight-adjusted appropriate prophylactic dose at admission, with an increase to intermediate intensity or full therapeutic dose based on clinical parameters [64]. On $11^{\text {th }}$ April 2020 the Italian drug agency (AIFA) included LMW heparin among the drugs available for the treatment of COVID-19 patients (https://aifa. gov.it/-/covid-19-scheda-informativa-aifa-su-eparine-a-basso-pesomolecolare).

Interestingly, a recent retrospective study in 324 non-critically ill patients hospitalised with COVID-19 has shown that the rates of relevant bleeding events and mortality were higher in patients receiving (sub)therapeutic doses of heparin (as unfractionated, LMW, or fondaparinux) than in those given prophylactic doses [65].

The above findings suggest that in non-hospitalised patients with mild COVID-19, the benefit of prophylactic administration of LMW heparin could extend beyond the prevention of thromboembolism in bedridden patients to control the possible initial activation of coagulation in the lung and other organs. Moreover, the evidence that heparin may protect the endothelium [66-68] and decrease the level of inflammatory biomarkers $[62,69,70]$ further supports the recommendation that COVID-9 patients be treated with this drug at home, as it can impact microcirculatory dysfunction and possibly limit organ damage[70].

\section{Anti-platelet drugs}

Anti-platelet agents are also currently used to prevent thromboembolism. Nevertheless, the scarce information regarding the use of these medicines in COVID-19 patients precludes us recommending them for non-hospitalised patients with SARS-CoV-2 infection for thromboembolism prophylaxis.

Dipyridamole, an old anti-platelet drug, is used to prevent cardiac valve-related thromboembolism [71]. Notably, in silico and in vitro evidence has shown that dipyridamole exhibits direct antiviral effects by binding and neutralising the SARS-CoV-2 component Mpro [72]. This is supported by results from a small clinical trial in Wuhan that demonstrate that dipyridamole had beneficial effects on preventing progression to severe stages of the disease and/or lethal outcomes when administered in moderate to severe COVID-19 patients [73]. Furthermore, dipyridamole may blunt the progressive increase in D-dimer blood levels in these patients, which closely correlates with pulmonary embolism and vascular thrombosis, eventually positively affecting the unfavourable prognosis of the disease [73]. Interestingly, dipyridamole has been also shown in vitro to suppress SARS-CoV-2 replication [73].

However, so far data supporting the use of dipyridamole in hospitalised COVID-19 patients are scanty, as it is unknown whether the drug can be safely combined with LMW heparin in these patients.

\section{Oxygen therapy}

In the early phase of the disease, possibly before pulmonary symptoms manifest, in the presence of progressively decreasing oxygen saturation - as indicated by oximeter - or following a first episode of dyspnoea or wheezing, gentle oxygen supply is recommended.

An additional helpful step for the physician in identifying initial pulmonary dysfunction, and thus the need for oxygen therapy, is the Quick Walking Test. This involves measuring $\mathrm{SpO}_{2}$ before and after the patient has walked as fast as he/she can for $20-30$ metres. The test is positive if, after the walk, $\mathrm{SpO}_{2}$ falls by more than $5 \%$.

Conventional oxygen therapy is suggested when the respiratory rate is $>14 / \mathrm{min}$ and oxygen saturation $\left(\mathrm{SpO}_{2}\right)<94-92 \%$, but is required with $\mathrm{SpO}_{2}<90 \%$ at room air $[74,75]$. With liquid oxygen, start with 8-10 litre/min and monitor $\mathrm{SpO}_{2}$ every 3-4 hours. Titrate oxygen flow rate to reach target $\mathrm{SpO}_{2}>94 \%$. Then the rate of oxygen administration can be reduced to $4-5$ litre/min (but continue $\mathrm{SpO}_{2}$ monitoring every 3-4 hours). With gaseous $\mathrm{O}_{2}$ start with 2.5-3.0 litre/min, but monitor $\mathrm{SpO}_{2}$ more frequently than with liquid oxygen, and titrate flow rates to reach target $\mathrm{SpO}_{2}>94 \%$. Should patients be poorly responsive to high $\mathrm{O}_{2}$ administration, consider hospitalisation, if feasible.

Oxygen can be administered using nasal cannulas or mask, which does not require sedation, so patients can participate in their treatment. This treatment should be combined with training patients in techniques that are helpful for managing breathlessness, including positioning, pursed-lip breathing and breathing exercises [76]. It should also be considered that severe breathlessness often causes patients anxiety, which in turn contributes to further increasing shortness of breath [76].

\section{Other treatments}

\section{Antibiotics}

Antibiotics are not mandatory, but sometimes necessary. This is the case of COVID-19 patients with bacterial pneumonia or suspected secondary bacterial upper respiratory tract infections, or particularly fragile, or when hematochemical inflammatory indexes (CRP, neutrophil count) are markedly altered. In such instances, we advise the administration of azithromycin, a macrolide $(500 \mathrm{mg} /$ day p.o for 6 days). Should the patient be at risk of or with a history of cardiac arrhythmia, cefixime ( $400 \mathrm{mg} /$ day p.o for 6 days) can be considered as alternative to azithromycin.

The antibiotics are often necessary. Indeed, several pieces of evidence indicate that many COVID-19 patients die of secondary bacterial infections rather than of the SARS-CoV-2 viral infection itself. In a Chinese cohort of 247 hospitalised COVID-19 patients, $15 \%$ acquired bacterial infections; of these, $50 \%$ died [4]. This is not unique to SARS-CoV-2 infection, since secondary bacterial pneumonia 
was the major cause of death during other major respiratory viral outbreaks (e.g 150 out 300 thousand people during the $2009 \mathrm{H} 1 \mathrm{N1}$ infection, and the majority of people during the 1918 Spanish flu). Moreover, bacterial co/secondary infection further increases morbidity and mortality of influenza infection, with Streptococcus pneumoniae, Haemophilus influenzae, and Staphyloccocus aureus reported as the most common causes [77]. Thus, azithromycin could be considered for non-hospitalised COVID-19-patients when physicians suspect a secondary bacterial infection of the lower or upper respiratory tract, in fragile patients and when laboratory inflammatory tests are markedly altered.

The use of azithromycin has raised some concerns because this drug, as it occurs with other macrolides, can block ion channels and may affect the cardiac electrical pattern [78]. On the other hand, in a Cochrane review, the use of macrolide antibiotics, including azithromycin, was not associated with a higher risk of cardiac disorders compared to placebo [79].

\section{Chloroquine and hydroxychloroquine}

Given the limited evidence of efficacy and many warnings about major side effects and the risk of patient death, at this stage we cannot recommend hydroxychloroquine, alone or in combination with azithromycin, to treat non-hospitalised patients with COVID-19.

While waiting for vaccines for SARS-CoV-2 and new investigational antiviral drugs, attention has focused on repurposing agents previously used to treat SARS-CoV and MERS-CoV infections, though with inconsistent results [7]. Chloroquine and hydroxychloroquine, two anti-malarial drugs that are also used to treat chronic inflammatory diseases such as lupus erythematosus and rheumatoid arthritis, initially received intense consideration [80]. Preliminary evidence of the efficacy of chloroquine/hydroxychloroquine treatment in COVID-19 patients was mainly confined to an unpublished Chinese study on 100 patients with chloroquine, and a French trial on 20 COVID-19 patients that demonstrated that hydroxychloroquine reduced viral load in nasal swabs, but no clinical outcomes were provided [81]. However, the initial optimism about the use of these medications was not supported by the results of subsequent randomised controlled trials. Boulware et al. carried out a randomized, double-blind, placebo-controlled trial in 821 asymptomatic participants who had household or occupational exposure to someone with confirmed COVID-19. Hydroxychloroquine did not prevent illness compatible with COVID-19 when used as postexposure prophylaxis within 4 days after exposure [82]. As a further proof of the lack of efficacy of prophylactic use of hydroxychloroquine, a very recent observational population-based cohort study showed no evidence of a difference in COVID-19 mortality among people who received this drug for treatment of rheumatological disease before the COVID-19 outbreak in United Kingdom [83]. The RECOVERY trial found that, among 4716 patients hospitalised with COVID-19, hydroxychloroquine did not reduce 28 -day mortality when compared to usual standard of care. Patients randomized to hydroxychloroquine had a longer median hospital stay and were less likely to be discharged alive within 28 days than those allocated to usual care [84]. In another randomised controlled trial that was performed in Brazil in 667 hospitalised patients with mild to moderate COVID-19, the use of hydroxychloroquine compared with standard care did not improve clinical status at 15 days, assessed by a six-level ordinary scale ranging from not hospitalized to death [85]. These findings have been confirmed by a placebo-controlled randomized clinical trial conducted at 34 hospitals in US [86]. Among adults hospitalized with respiratory illness from COVID-19, treatment with hydroxychloroquine, compared with placebo, did not significantly improve clinical status at day 14 . In addition, the clinical use of both chloroquine and hydroxychloroquine is complicated by several adverse events, including QTc prolongation, hypoglycaemia, neuropsychiatric effects, and retinopathy [87]. Evidence of potential harm from these drugs is also beginning to appear in COVID-19 patients. A clinical trial in Brazil in which 81 patients hospitalised for COVID-19 were treated with chloroquine and azithromycin was halted after investigators recorded more deaths and an increased risk of arrhythmia in the group receiving the higher of two doses [88]. The increased risk of death was also documented among patients given hydroxychloroquine, compared to those not receiving this treatment, in a study of 368 US veterans treated for COVID-19 [89]. More recently, the Food and Drug Administration (FDA) also warned of the dangers of hydroxychloroquine for COVID-19 patients, citing serious adverse effects on the heart and a high risk of death.

\section{In summary}

During the early phase of COVID-19, patients are usually not seriously ill with acute respiratory distress, but present a variety of symptoms, including fever, cough, tiredness, shortness of breath and chills, a sore throat, headache, musculoskeletal pain, and a new loss of taste or smell. For non-hospitalised patients with one or more of these symptoms, we can recommend few simple treatments, as briefly summarized here. Recommended treatments should start immediately when COVID-19 early symptoms appear without waiting results of a nasopharyngeal swab, if any.

\section{Non-steroidal anti-inflammatory drugs (NSAIDs)}

COX-2 inhibitors: (for myalgias and/or arthralgias or other painful symptoms)

\section{Nimesulide *}

$100 \mathrm{mg}$ b.i.d p.o, after a meal, for a maximum of 12 days.

Or

\section{Celecoxib *}

Initial oral dose of $400 \mathrm{mg}$, followed by a second dose $200 \mathrm{mg}$ on the first day of therapy. In the following days, up to a maximum of $400 \mathrm{mg} /$ day (200 mg twice a day) should be given as needed.

* Should the patient have fever $\left(\geq 37.3^{\circ} \mathrm{C}\right)$ or develop laboratory signs of hepatotoxicity associated with nimesulide or there are contraindications to celecoxib, these drugs should be substituted with aspirin (a COX-1 and COX-2 inhibitor) (500 mg twice a day p.o. - after a meal). These treatments should be associated with a proton pump inhibitor (e.g. lansoprazole - 30 $\mathrm{mg} /$ day; or omeprazole - $20 \mathrm{mg} /$ day; or pantoprazole - $20 \mathrm{mg} /$ day).

After approximately 3 days from the onset of symptoms (or more days are elapsed and the physician sees the patient for the first time), a series of hematochemical tests should be performed (blood cell count, D-dimer, CRP, creatinine, fasting blood glucose, ALT). Should inflammatory indexes (CRP, neutrophil count), ALT, and D-dimer be in the normal range, nimesulide/celecoxib (or aspirin) treatment will continue.

Corticosteroids: ${ }^{*}$ (for persistent fever or musculoskeletal pain or when few days later hematochemical tests were repeated and even mild increase of inflammatory indexes - CRP, neutrophil count - are documented, or cough and oxygen saturation (SpO2) $<94-92 \%$ occur)

\section{Dexamethasone *}

$8 \mathrm{mg}$ p.o for 3 days, then tapered to $4 \mathrm{mg}$ for a further 3 days, and then to $2 \mathrm{mg}$ for 3 days. That makes $42 \mathrm{mg}$ dexamethasone total over 9 days. 


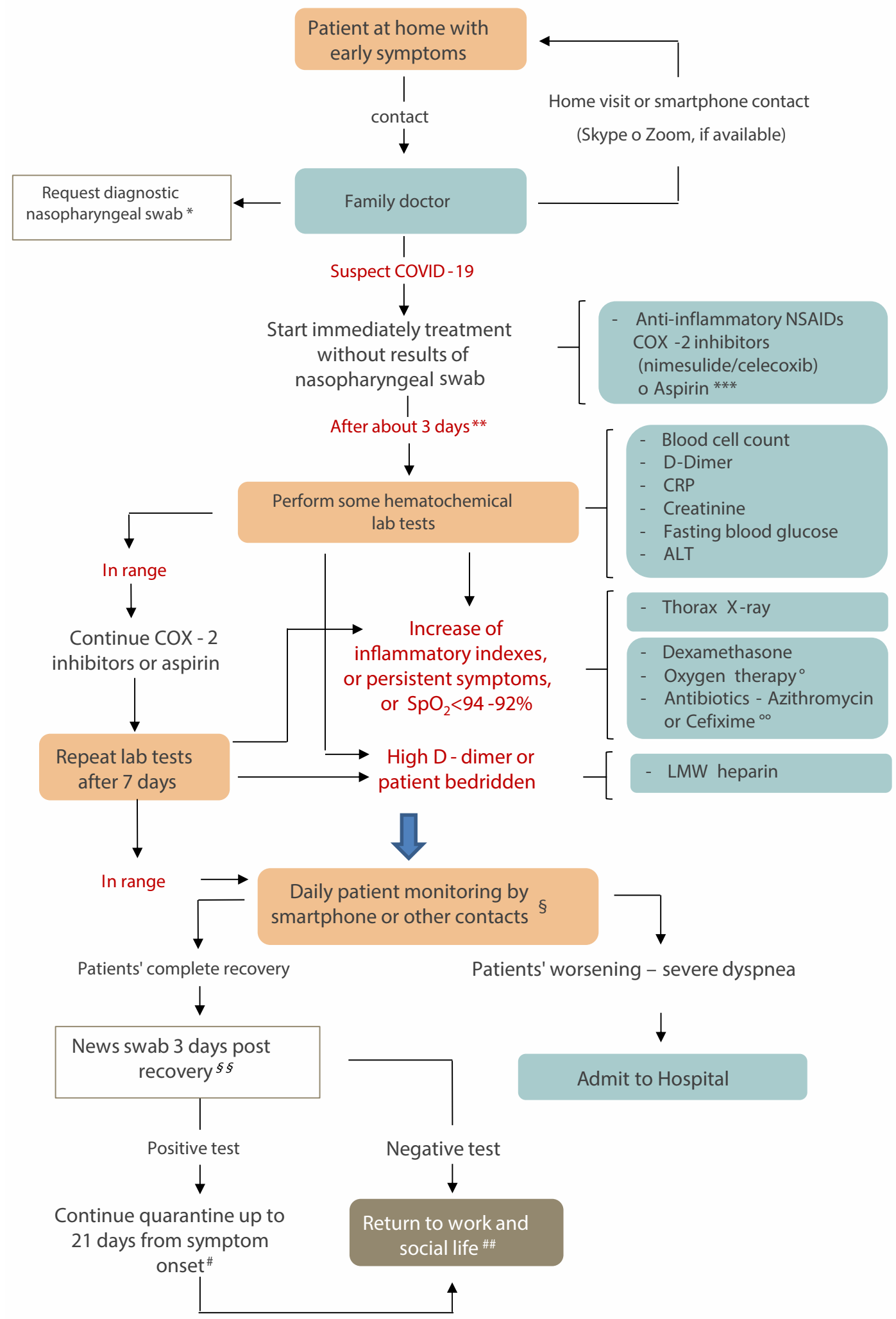

Figure 1. Flow chart of recommended steps for family physicians to monitor non-hospitalised patients in the early phase of COVID-19. *If feasible, according to local/national healthcare system. ** From the onset of symptoms (or more days have elapsed and the physician sees the patient for the first time). *** If fever ( $\geq 37.3^{\circ} \mathrm{C}$ ) or laboratory evidence of nimesulide-induced hepatotoxicity or contraindication to celecoxib. ${ }^{\circ}$ With mild dyspnoea or wheezing. ${ }^{\circ}$ Suspected secondary bacterial infection in the upper or lower respiratory tract; fragile patients. $\S$ Particular care to dyspnoea/wheezing (possibly SpO2 monitoring with oximeter). §§ Ten days from the symptom onset, of whom 3 days without symptoms (excluding anosmia, ageusia/ dysgeusia). \# Can be changed by health authorities. \#\# Useful to assess serology tests - immune response 
${ }^{\star}$ Duration of corticosteroid treatment also depends on the clinical evolution of the disease

\section{Anticoagulants:}

Low-molecular weight (LMW) heparin* (when the hematochemical tests show even a mild increase of D-dimer or for thromboembolism prophylaxis for bedridden patients)

Enoxaparin, at the prophylactic daily dose of 4000 U.I subcutaneously - i.e. $40 \mathrm{mg}$ enoxaparin. Treatment recommended for at least 7-14 days, independently of the patient recovering mobility.

*unless contraindicated (e.g., ongoing bleeding or platelet count $<25$ $\left.x 10^{9} / \mathrm{L}\right)$

\section{Oxygen therapy}

Gentle oxygen supply in the early phase of the disease, possibly before pulmonary symptoms manifest, in the presence of progressively decreasing oxygen saturation - as indicated by oximeter - or following a first episode of dyspnoea or wheezing.

Conventional oxygen therapy is suggested when the respiratory rate is $>14 / \mathrm{min}$ and oxygen saturation $\left(\mathrm{SpO}_{2}\right)<94-92 \%$, but is required with $\mathrm{SpO}_{2}<90 \%$ at room air. With liquid oxygen, start with 8-10 litre/ min and monitor $\mathrm{SpO}_{2}$ every 3-4 hours. Titrate oxygen flow rate to reach target $\mathrm{SpO}_{2}>94 \%$. Then the rate of oxygen administration can be reduced to 4-5 litre/min (but continue $\mathrm{SpO}_{2}$ monitoring every 3-4 hours). With gaseous $\mathrm{O}_{2}$ start with 2.5-3.0 litre/min, but monitor $\mathrm{SpO}_{2}$ more frequently than with liquid oxygen, and titrate flow rates to reach target $\mathrm{SpO}_{2}>94 \%$. Should patients be poorly responsive to high $\mathrm{O}_{2}$ administration, consider hospitalisation, if feasible.

\section{Antibiotics}

Azithromycin: ${ }^{*}$ (with bacterial pneumonia or suspected secondary bacterial upper respiratory tract infections, or in particularly fragile patients, or when hematochemical inflammatory indexes (CRP, neutrophil count) are markedly altered)

$500 \mathrm{mg} /$ day p.o for 6 days.

* Should the patient be at risk of or with a history of cardiac arrhythmia, cefixime (400 mg/day p.o for 6 days) can be considered as alternative to azithromycin.

Moreover, as a general recommendations, patients on chronic therapy with anti-hypertensive drugs, such as angiotensin converting enzyme (ACE) inhibitors or angiotensin II type 1 receptor (ARB) antagonists, should not discontinue these medicines, since they do not affect the course of COVID-19 [90]. However, blood pressure should be monitored, and drug dosing adjusted, if needed.

In addition, we recommend that physicians ask patients or relatives for the date of the first signs of illness, an important step in monitoring a SARS-CoV-2 infection. Indeed, although the evolution of symptoms is different from patient to patient, days 5 through 10 tend to be the time during which respiratory complications are most likely to develop, particularly in elderly patients and patients with pre-existing conditions, such as high blood pressure, obesity or diabetes. Younger COVID-19 patients who go on to develop complications may develop these at a slightly later point, potentially only on days 10 to 12 . Most who reach day 14 without developing more serious symptoms are likely to have begun to recover. On this line the flow-chart reported in the
Figure 1 shows recommend steps for family physicians to monitor nonhospitalised patients in the early phase of COVID-19.

These recommendations may be helpful not only to industrialised countries, which are witnessing the dramatic spread of the epidemic through second or even third waves, but also, and probably even more so, to low- and middle-income countries in Latin America and Africa. In these countries, a lack of hospital infrastructure and access to costly treatments may exacerbate the risk of dying from the virus, further highlighting disparities in access to healthcare globally.

\section{References}

1. WHO (2020) Minimum requirements for infection prevention and control (IPC) programmes. World Health Organization website.

2. Hopman J, Allegranzi B, Mehtar S (2020) Managing COVID-19 in low- and middleincome countries. JAMA 323: 1549-1550 [Crossref]

3. Johns Hopkins CSSE (2020) COVID-19 Map - Johns Hopkins Coronavirus Resource Center. Accessed November 9. Available at: www.coronavirua.jhu.edu.

4. Zhou F, Yu T, Du R, et al. (2020) Clinical course and risk factors for mortality of adult inpatients with COVID-19 in Wuhan, China: a retrospective cohort study. Lancet 395 1054-1062. [Crossref]

5. Guan WJ, Ni ZY, Hu Y, et al. (2020) Clinical characteristics of coronavirus disease 2019 in China. N Engl J Med 382: 1708-1720.

6. Kupferschmidt K, Cohen J (2020) Race to find COVID-19 treatments accelerates. Science 367: 1412-1413.

7. Sanders JM, Monogue ML, Jodlowski TZ, et al. (2020) Pharmacologic treatments fo coronavirus disease 2019 (COVID-19): A Review. JAMA 323: 1824-1836. [Crossref]

8. Perico N, Suter F, Remuzzi G (2020) A recurrent question from a primary care physician: How should I treat my COVID-19 patients at home? Clin Med Invest 5: 1-8.

9. Cullen L, Kelly L, Connor SO, et al. (1998) Selective cyclooxygenase-2 inhibition by nimesulide in man. J Pharmacol Exp Ther 287: 578-582. [Crossref]

10. EMEA (2020) European Agency for the Evaluation of Medicinal Products. Assessment report for Nimesulide containing medicinal products for systemic use, 20 January 2012 Available at http://www.ema.europa.eu/docs/en_GB/document_library/Referrals document/Nimesulide_31/WC500125574.pdf.

11. Traversa G, Bianchi C, Da Cas R, et al. (2003) Cohort study of hepatotoxicity associated with nimesulide and other non-steroidal anti-inflammatory drugs. BMJ 327 : 18-22. [Crossref]

12. Lee CH, Wang JD, Chen PC (2010) Increased risk of hospitalization for acute hepatitis in patients with previous exposure to NSAIDs. Pharmacoepidemiol Drug Saf 19: 708714

13. Donati M, Conforti A, Lenti MC, et al. (2016) Risk of acute and serious liver injury associated to nimesulide and other NSAIDs: data from drug-induced liver injury casecontrol study in Italy. Br J Clin Pharmacol 82: 238-248. [Crossref]

14. Brooks PM, Day RO (1991) Nonsteroidal antiinflammatory drugs--differences and similarities. N Engl J Med 324: 1716-1725.

15. Ricciotti E, FitzGerald GA (2011) Prostaglandins and inflammation. Arterioscler Thromb Vasc Biol 31: 986-1000.

16. Voiriot G, Philippot Q, Elabbadi A, et al. (2020) Risks Related to the Use of NonSteroidal Anti-Inflammatory Drugs in Community-Acquired Pneumonia in Adult and Pediatric Patients. J Clin Med 8: 768. [Crossref]

17. Little $\mathrm{P}$ (2020) Non-steroidal anti-inflammatory drugs and covid-19. BMJ 368: $\mathrm{m} 1185$.

18. Little P, Moore M, Kelly J, et al. (2013) Ibuprofen, paracetamol, and steam for patients with respiratory tract infections in primary care: pragmatic randomised factorial trial. BMJ 347:f6041.

19. FitzGerald GA (2020) Misguided drug advice for COVID-19. Science 367:1434 [Crossref]

20. Torjesen I (2020) Covid-19: ibuprofen can be used for symptoms, says UK agency, but reasons for change in advice are unclear. BMJ 369:m1555.

21. Ikonomidis I, Andreotti F, Economou E, et al. (1999) Increased proinflammatory cytokines in patients with chronic stable angina and their reduction by aspirin Circulation 100: 793-798. 
22. Chow JH, Khanna AK, Kethireddy S, et al. (2020) Aspirin Use is associated with decreased mechanical ventilation, icu admission, and in-hospital mortality in hospitalized patients with COVID-19. Anesth Analg 2020: doi:10.1213/ANE.0005292.. [Crossref]

23. McKay GA, Walters MR (2013) Non-Opioid Analgesics". lecture notes clinical pharmacology and therapeutics (9th ed.). Hoboken: Wiley.

24. Ghanem CI, Perez MJ, Manautou JE, et al. (2016) Acetaminophen from liver to brain: New insights into drug pharmacological action and toxicity. Pharmacol Res 109: 119131.

25. Besedovsky L, Lange T, Haack M (2019) The sleep-immune crosstalk in health and disease. Physiol Rev 99: 1325-1380. [Crossref]

26. Silverstein FE, Faich G, Goldstein JL, et al. (2000) Gastrointestinal toxicity with celecoxib vs nonsteroidal anti-inflammatory drugs for osteoarthritis and rheumatoid arthritis: the CLASS study: A randomized controlled trial. Celecoxib Long-term Arthritis Safety Study. JAMA 284: 1247-1255.

27. Bombardier C, Laine L, Reicin A, et al. (2000) Comparison of upper gastrointestinal toxicity of rofecoxib and naproxen in patients with rheumatoid arthritis. VIGOR Study Group. N Engl J Med 343: 1520-1528.

28. Bhala N, Emberson J, Merhi A, et al. (2013) Vascular and upper gastrointestinal effects of non-steroidal anti-inflammatory drugs: meta-analyses of individual participant data from randomised trials. Lancet 382: 769-779.

29. Moore N (2020) Coronary risks associated with diclofenac and other NSAIDs: An update. Drug Saf 43: 301-318.

30. Clave S, Rousset-Rouviere C, Daniel L, et al. (2019) The invisible threat of nonsteroidal anti-inflammatory drugs for kidneys. Front Pediatr 7: 520. [Crossref]

31. Zhang X, Donnan PT, Bell S, et al. (2017) Non-steroidal anti-inflammatory drug induced acute kidney injury in the community dwelling general population and people with chronic kidney disease: systematic review and meta-analysis. BMC Nephrol 18: 256.

32. Cruz-Topete D, Cidlowski JA (2015) One hormone, two actions: anti- and proinflammatory effects of glucocorticoids. Neuroimmunomodulation 22: 20-32.

33. Stockman LJ, Bellamy R, Garner P (2006) SARS: systematic review of treatmen effects. PLoS Med 3: e343. [Crossref]

34. Arabi YM, Mandourah Y, Al-Hameed F, et al. (2018) Corticosteroid therapy for critically ill patients with Middle East respiratory syndrome. Am J Respir Crit Care Med 197: 757-767.

35. Russell CD, Millar JE, Baillie JK (2020) Clinical evidence does not support corticosteroid treatment for 2019-nCoV lung injury. Lancet 395: 473-475.

36. Ni YN, Chen G, Sun J, et al. (2019) The effect of corticosteroids on mortality of patients with influenza pneumonia: a systematic review and meta-analysis. Crit Care 23: 99.

37. Yang Z, Liu J, Zhou Y, et al. (2020) The effect of corticosteroid treatment on patient with coronavirus infection: a systematic review and meta-analysis. J Infect 81: e13-e20. [Crossref]

38. Wu C, Chen X, Cai Y, et al. (2020) Risk factors associated with acute respiratory distress syndrome and death in patients with coronavirus disease 2019 pneumonia in Wuhan, China. JAMA Intern Med 180: 934-943. [Crossref]

39. Horby P, Lim WS, Emberson JR, et al. (2020) Dexamethasone in hospitalized patients with Covid-19 - preliminary report. $N$ Engl J Med 2020: doi:10.1056/NEJMoa2021436 [Crossref]

40. Lamontagne F, Agoritsas T, Macdonald H, et al. (2020) A living WHO guideline on drugs for covid-19. BMJ 370: $\mathrm{m} 3379$

41. Shang L, Zhao J, Hu Y, et al. (2020) On the use of corticosteroids for 2019-nCoV pneumonia. Lancet 395: 683-684.

42. Zhao JP, Hu Y, Du RH, et al. (2020) Expert consensus on the use of corticosteroid in patients with 2019-nCoV pneumonia. Zhonghua Jie He He Hu Xi Za Zhi 43: 183-184.

43. Zhou W, Liu Y, Tian D, et al. (2020) Potential benefits of precise corticosteroids therapy for severe 2019-nCoV pneumonia. Signal Transduct Target Ther 5:18. [Crossref]

44. Nicastri E, Petrosillo N, Bartoli TA, et al. (2020) National Institute for the Infectious Diseases "L. Spallanzani", IRCCS. Recommendations for COVID-19 clinical management. Infect Dis Rep 12:8543.
45. Russell B, Moss C, Rigg A, et al. (2020) COVID-19 and treatment with NSAIDs and corticosteroids: should we be limiting their use in the clinical setting? Ecancermedicalscience 14: 1023.

46. Lee KY (2017) Pneumonia, acute respiratory distress syndrome, and early immunemodulator therapy. Int J Mol Sci 18: 388. [Crossref]

47. Lee KY, Rhim JW, Kang JH (2020) Early preemptive immunomodulators (corticosteroids) for severe pneumonia patients infected with SARS-CoV-2. Clin Exp Pediatr 63: 117-118.

48. Zhai P, Ding Y, Wu X, et al. (2020) The epidemiology, diagnosis and treatment of COVID-19. Int J Antimicrob Agents 55: 105955. [Crossref]

49. Gray E, Hogwood J, Mulloy B (2012) The anticoagulant and antithrombotic mechanisms of heparin. Handb Exp Pharmacol 2012: 43-61.

50. Giannis D, Ziogas IA, Gianni P (2020) Coagulation disorders in coronavirus infected patients: COVID-19, SARS-CoV-1, MERS-CoV and lessons from the past. J Clin Virol 127: 104362 .

51. Klok FA, Kruip M, van der Meer NJM, et al. (2020) Incidence of thrombotic complications in critically ill ICU patients with COVID-19. Thromb Res 191: 145-147. [Crossref]

52. Fogarty H, Townsend L, Ni Cheallaigh C, et al. (2020) COVID-19 coagulopathy in Caucasian patients. Br J Haematol 189: 1044-1049 [Crossref]

53. Tang N, Li D, Wang X, et al. (2020) Abnormal coagulation parameters are associated with poor prognosis in patients with novel coronavirus pneumonia. $J$ Thromb Haemost 18: 844-847.

54. Sakka M, Connors JM, Hekimian G, et al. (2020) Association between D-Dimer levels and mortality in patients with coronavirus disease 2019 (COVID-19): a systematic review and pooled analysis. J Med Vasc 45: 268-274.

55. Yao XH, Li TY, He ZC, et al. (2020) A pathological report of three COVID-19 cases by minimally invasive autopsies. Zhonghua Bing Li Xue Za Zhi 49: E009.

56. Dolhnikoff M, Duarte-Neto AN, de Almeida Monteiro RA, et al. (2020) Pathological evidence of pulmonary thrombotic phenomena in severe COVID-19. J Thromb Haemost 18: 1517-1519. [Crossref]

57. Carsana L, Sonzogni A, Nasr A, et al. (2020) Pulmonary post-mortem findings in a series of COVID-19 cases from northern Italy: a two-centre descriptive study. Lancet Infect Dis 20:1135-1140.

58. Whyte CS, Morrow GB, Mitchell JL, et al. (2020) Fibrinolytic abnormalities in acute respiratory distress syndrome (ARDS) and versatility of thrombolytic drugs to treat COVID-19. J Thromb Haemost 18: 1548-1555. [Crossref]

59. Subramaniam S, Scharrer I (2018) Procoagulant activity during viral infections. Front Biosci (Landmark Ed) 23: 1060-1081.

60. Tang N, Bai H, Chen X, et al. (2020) Anticoagulant treatment is associated with decreased mortality in severe coronavirus disease 2019 patients with coagulopathy. $J$ Thromb Haemost 18: 1094-1099.

61. Paranjpe I, Fuster V, Lala A, et al. (2020) Association of treatment dose anticoagulation with in-hospital survival among hospitalized patients with COVID-19. J Am Coll Cardiol 76: 122-124 [Crossref]

62. Shi C, Wang C, Wang H, et al. (2020) The potential of low molecular weight heparin to mitigate cytokine storm in severe COVID-19 patients: A retrospective cohort study. Clin Transl Sci 2020: doi:10.41/cts.12880. [Crossref]

63. Thachil J, Tang N, Gando S, et al. (2020) ISTH interim guidance on recognition and management of coagulopathy in COVID-19. J Thromb Haemost 18: 1023-1026.

64. Thachil J, Juffermans NP, Ranucci M, et al. (2020) ISTH DIC subcommittee communication on anticoagulation in COVID-19. J Thromb Haemost 18: 2138-2144.

65. Pesavento R, Ceccato D, Pasquetto G, et al. (2020) The hazard of (sub)therapeutic doses of anticoagulants in non-critically ill patients with Covid-19: The Padua province experience. J Thromb Haemost 18: 2629-2635. [Crossref]

66. Iba T, Hashiguchi N, Nagaoka I, et al. (2015) Heparins attenuated histone-mediated cytotoxicity in vitro and improved the survival in a rat model of histone-induced organ dysfunction. Intensive Care Med Exp 3: 36.

67. Zhu C, Liang Y, Li X, et al. (2019) Unfractionated heparin attenuates histone-mediated cytotoxicity in vitro and prevents intestinal microcirculatory dysfunction in histoneinfused rats. J Trauma Acute Care Surg 87: 614-622.

68. Liu Y, Mu S, Li X, et al. (2019) Unfractionated heparin alleviates sepsis-induced acute lung injury by protecting tight junctions. J Surg Res 238: 175-185. [Crossref] 
69. Mousavi S, Moradi M, Khorshidahmad T, et al. (2015) Anti-inflammatory effects of heparin and its derivatives: A systematic review. Adv Pharmacol Sci 2015: 507151.

70. Thachil J (2020) The versatile heparin in COVID-19. J Thromb Haemost 18: 10201022 .

71. Renney JT, O'Sullivan EF, Burke PF (1976) Prevention of postoperative deep vein thrombosis with dipyridamole and aspirin. $\operatorname{Br}$ Med $J$ 1: 992-994. [Crossref]

72. Verma DK, Kapoor S, Das S, et al. (2020) Potential inhibitors of SARS-CoV-2 Main protease (Mpro) identified from the library of FDA approved drugs using molecular docking studies. Preprints (www.preprints.org)

73. Liu X, Li Z, Liu S, et al. (2020) Potential therapeutic effects of dipyridamole in the severely ill patients with COVID-19. Acta Pharm Sin B 10: 1205-1215. [Crossref]

74. CDC (2020) Clinical management of critically ill adults with COVID-19. Clinical Outreach and Communication Activity (COCA) webinar, April 2, 2020.

75. Federazione Regionale degli Ordini dei Medici Chirurghi e degli Odontoiatri dellaLombardia (2020) Vademecum della cura delle persone con infezione da SARS-CoV-2 non ospedalizzate. Available at: https://www.omceomi.it/docs/defaultsource/default-document-library/fromceo-vademecum-della-cura-delle-personecon-infezione-da-sars-cov-2-nonspedalizzate23accbd0b11066cb9190ff0000bb5bce. pdf?sfvrsn $=0$.

76. NICE (2020) Managing COVID-19 symptoms (including at the end of life) in the community: summary of NICE guidelines. BMJ 369: m1461. [Crossref]

77. Morris DE, Cleary DW, Clarke SC (2017) Secondary bacterial infections associated with influenza pandemics. Front Microbiol 8: 1041.

78. Lu ZK, Yuan J, Li M, et al. (2015) Cardiac risks associated with antibiotics: azithromycin and levofloxacin. Expert Opin Drug Saf 14: 295-303.

79. Hansen MP, Scott AM, McCullough A, et al. (2019) Adverse events in people taking macrolide antibiotics versus placebo for any indication. Cochrane Database Syst Rev 1: CD011825. [Crossref]

80. Savarino A, Boelaert JR, Cassone A, et al. (2003) Effects of chloroquine on viral infections: an old drug against today's diseases? Lancet Infect Dis 3: 722-727.
81. Gautret P, Lagier JC, Parola P, et al. (2020) Hydroxychloroquine and azithromycin as a treatment of COVID-19: results of an open-label non-randomized clinical trial. Int $J$ Antimicrob Agents 56: 105949. [Crossref]

82. Boulware DR, Pullen MF, Bangdiwala AS, et al. (2020) A randomized trial of hydroxychloroquine as postexposure prophylaxis for Covid-19. $N$ Engl J Med 383: 517-525.

83. Rentsch CT, DeVito NJ, MacKenna B, et al. (2020) Effect of pre-exposure use of hydroxychloroquine on COVID-19 mortality: a population-based cohort study in patients with rheumatoid arthritis or systemic lupus erythematosus using the OpenSAFELY platform. Lancet Rheumatol 2020

84. Horby P, Mafham M, Linsell L, et al. (2020) Effect of hydroxychloroquine in hospitalized patients with Covid-19. N Engl J Med 383: 2030-2040. [Crossref]

85. Cavalcanti AB, Zampieri FG, Rosa RG, et al. (2020) Hydroxychloroquine with or without Azithromycin in Mild-to-Moderate Covid-19. N Engl J Med 383: 2041-2052. [Crossref]

86. Self WH, Semler MW, Leither LM, et al. (2020) Effect of hydroxychloroquine on clinical status at 14 days in hospitalized patients with COVID-19: A randomized clinical trial. JAMA 2020: e2022240. [Crossref]

87. Kalil AC (2020) Treating COVID-19-off-label drug use, compassionate use, and randomized clinical trials during pandemics. JAMA 323: 1897-1898. [Crossref]

88. Borba MGS, Val FFA, Sampaio VS, et al. (2020) Effect of high vs low doses of chloroquine diphosphate as adjunctive therapy for patients hospitalized with severe acute respiratory syndrome coronavirus 2 (SARS-CoV-2) infection: A randomized clinical trial. JAMA Netw Open 3: e208857. [Crossref]

89. Magagnoli J, Narendran S, Pereira F, et al. (2020) Outcomes of hydroxychloroquine usage in united states veterans hospitalized with COVID-19. Med (N Y) 1: 1-14. [Crossref]

90. Mancia G, Rea F, Ludergnani M, et al. (2020) Renin-angiotensin-aldosterone system blockers and the risk of Covid-19. N Engl J Med 382: 2431-2440. [Crossref]

Copyright: (C2020 Suter F. This is an open-access article distributed under the terms of the Creative Commons Attribution License, which permits unrestricted use, distribution, and reproduction in any medium, provided the original author and source are credited. 